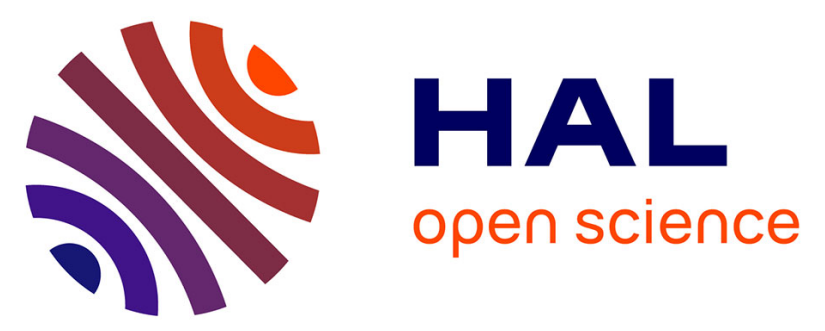

\title{
p -Anisaldehyde-Photosensitized Sulfonylcyanation of Chiral Cyclobutenes: Enantioselective Access to Cyclic and Acyclic Systems Bearing All-Carbon Quaternary Stereocenters
}

Vincent Pirenne, Iman Traboulsi, Lisa Rouvière, Jonathan Lusseau, Stéphane Massip, Dario M. Bassani, Frédéric Robert, Yannick Landais

\section{To cite this version:}

Vincent Pirenne, Iman Traboulsi, Lisa Rouvière, Jonathan Lusseau, Stéphane Massip, et al.. p Anisaldehyde-Photosensitized Sulfonylcyanation of Chiral Cyclobutenes: Enantioselective Access to Cyclic and Acyclic Systems Bearing All-Carbon Quaternary Stereocenters. Organic Letters, 2020, 22 (2), pp.575-579. 10.1021/acs.orglett.9b04345 . hal-02499993

\section{HAL Id: hal-02499993 https://hal.science/hal-02499993}

Submitted on 5 Mar 2020

HAL is a multi-disciplinary open access archive for the deposit and dissemination of scientific research documents, whether they are published or not. The documents may come from teaching and research institutions in France or abroad, or from public or private research centers.
L'archive ouverte pluridisciplinaire HAL, est destinée au dépôt et à la diffusion de documents scientifiques de niveau recherche, publiés ou non, émanant des établissements d'enseignement et de recherche français ou étrangers, des laboratoires publics ou privés. 


\section{p-Anisaldehyde-Photosensitized Sulfonyl-cyanation of Chiral Cyclobutenes. Enantioselective Access to Cyclic and Acyclic Systems Bearing All-carbon Quaternary Stereocenters.}

Vincent Pirenne, ${ }^{a, \ddagger}$ Iman Traboulsi, ${ }^{a, \ddagger}$ Lisa Rouvière, ${ }^{a}$ Jonathan Lusseau, ${ }^{a}$ Stéphane Massip, ${ }^{b}$ Dario M. Bassani, ${ }^{a}$ Frédéric Robert, ${ }^{a}$ and Yannick Landais* ${ }^{\text {a }}$

${ }^{a}$ University of Bordeaux, CNRS, Bordeaux INP, ISM, UMR 5255, F-33400, Talence, France.

${ }^{b}$ University of Bordeaux, European Institute of Chemistry and Biology (IECB), 2 Rue Robert Escarpit, 33600 Pessac, France

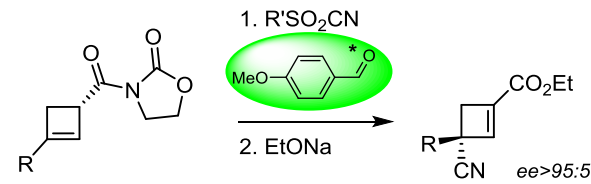

ABSTRACT: The photosensitized $p$-anisaldehyde mediated addition of sulfonylcyanides onto the to system of cyclobutenes is shown to afford highly functionalized cyclobutanes in high yields and diastereocontrol. The homochiral cyclobutene precursors are accessible on multi-gram scale in 2 steps through an asymmetric [2+2]-cycloaddition/vinyl thioether reduction sequence. The enantiopure cyclobutylnitriles can be elaborated further through $\mathrm{Sml}_{2}$-mediated ring-opening or converted into new enantiopure cyclobutenes through base-mediated sulfone elimination.

Chiral cyclopropanes and cyclobutanes constitute key fragments in a number of natural products and bioactive substrates relevant to pharmaceutical use. ${ }^{1}$ Among the small rings, cyclopropanes hold a special place and have therefore monopolized the attention of organic chemists due to their inherent ring strain, useful in ring expansion and ring-opening reactions. ${ }^{2}$ In contrast, cyclobutanes have attracted much less interest, although their incorporation in bioactive targets is becoming more popular in the context of drug design (e.g. mirogabalin, Scheme 1). ${ }^{1}$ Cyclopropanes and cyclobutanes can be constructed in many ways, ${ }^{3}$ including through addition onto their unsaturated analogues and highly strained cyclopropenes and cyclobutenes. ${ }^{4}$ Cyclopropenes thus show a high reactivity toward addition of organometallic species ${ }^{4 a-d}$ but, as expected, the extension of the strategy to cyclobutenes proved more difficult as illustrated by recent studies. ${ }^{5} \mathrm{~A}$ similar trend is observed in free-radical additions, where the reactivity of cyclobutenes was shown to be of the same order as cyclohexene, ${ }^{6}$ and lower to that of cyclopropenes. Radical additions to cyclopropenes ${ }^{6,7}$ and cyclobutenes ${ }^{8}$ are thus rare. Xanthate transfer addition reactions on these highly strained rings have however been described concomitantly by Zard, ${ }^{7 b}$ Saicic $^{6}$ and co-workers but the scope is narrow, and yields and diastereoselectivities moderate (Scheme 1a).

In the course of our studies on free-radical functionalization of olefins, we have developed a three-component carbocyanation of cyclopropenes which led to the formation of the corresponding cyclopropanes in satisfying yields and moderate diastereoselectivities. ${ }^{9}$ Our efforts to extend the strategy to the cyclobutene series proved nevertheless unsuccessful, illustrating the relatively poor reactivity of the $\pi$-system in cyclobutenes. The restricted access to chiral enantiopure cyclobutenes and the limited number of studies on additions onto cyclobutenes thus prompted us to develop a straightforward access to this class of olefin and to revisit their reactivity towards free-radical species.

Scheme 1. Free-radical functionalization of chiral cyclobutenes.

(a) Reported radical additions on cyclobutenes (Saicic and Zard) ${ }^{6,7 b}$

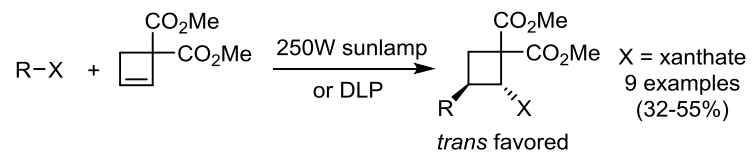

(b) This work
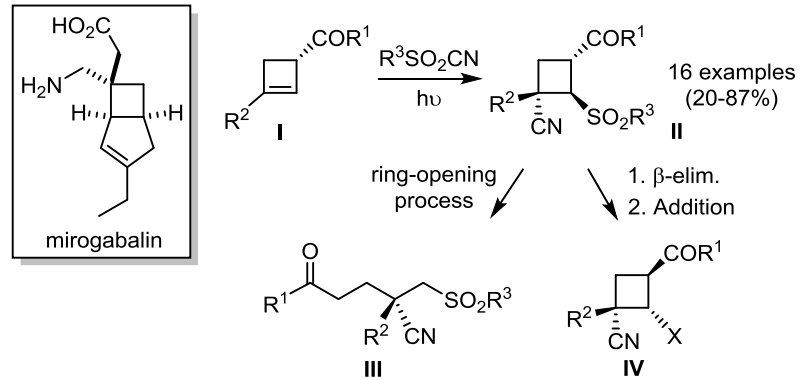
We report here on the development of a multi-gram scale enantioselective synthesis of cyclobutenes $\mathbf{I}$ and on the photocatalyzed addition of an electrophilic sulfonyl radical and a cyanide group across the $\pi$-system of I (Scheme $1 \mathrm{~b}$ ), which affords an access to highly functionalized cyclobutanes II in a completely regio- and diastereoselective manner. The subsequent functionalization of II is also documented, and includes regioselective free-radical cyclobutane-ring opening, providing enantioenriched cyanosulfones III bearing an all-carbon quaternary stereocenter, or new cyclobutenes, efficient Michael acceptors ultimately leading to tetra-substituted cyclobutanes IV, which are useful intermediates in stereoselective elaboration of more complex structural motifs.

Efficient routes to enantiopure cyclobutenes $^{10}$ are relatively rare as compared to the easy synthesis of parent cyclopropenes. ${ }^{11} \mathrm{~A}$ recent example of cyclopropenes-ring expansion into cyclobutenes related to $\mathrm{I}$ has been reported by Marek et al., ${ }^{12}$ but there is no general method for the enantioselective synthesis of cyclobutenes such as I (Scheme 1 ). ${ }^{13}$ We thus developed a rapid access to $\mathrm{I}$, based on the asymmetric [2+2] cycloaddition reaction between $\alpha, \beta$-unsaturated $\mathrm{N}$ acyloxazolidinones $\mathbf{1}$ and alkynyl sulfides $\mathbf{2 a - h}$ catalyzed by a cheap chiral titanium reagent, devised earlier by Narasaka and co-workers, ${ }^{10}$ which provided the corresponding cyclobutenyl sulfides $\mathbf{3 a}-\mathbf{h}$ in good yields and high enantioselectivities (Scheme 2 and $\mathrm{SI}$ ).

Scheme 2. Preparation of cyclobutenes 4a-h.
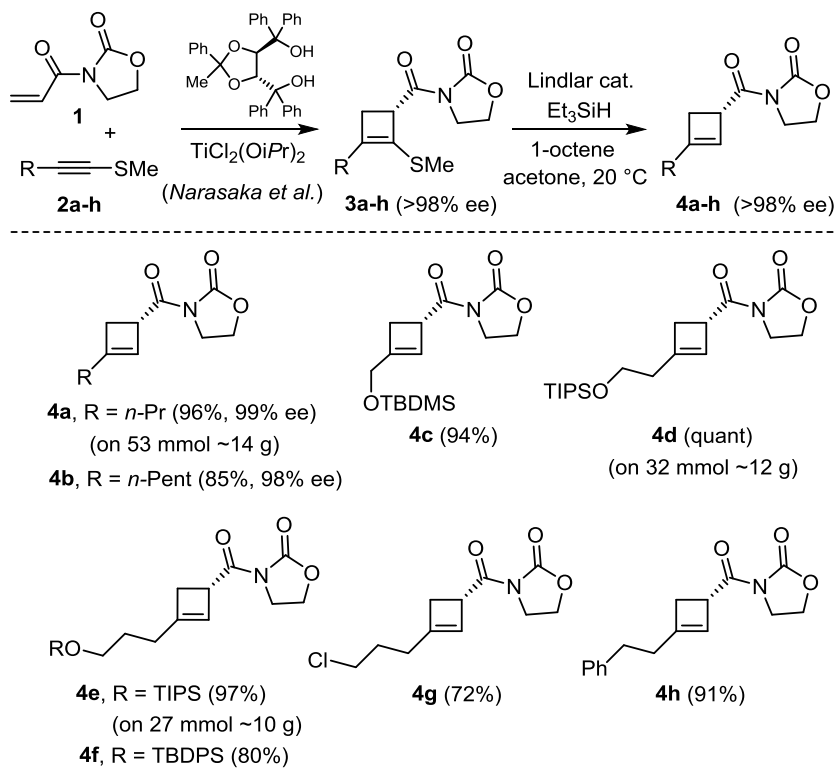

The removal of the SMe substituent was carried out using a combination of Lindlar's catalyst and a sacrificial alkene, ${ }^{14}$ allowing full conversion of $\mathbf{3 a}$ into $\mathbf{4 a}$ without over-reduction of the latter (Table S1). Noteworthy, careful measurement of the enantiomeric excess of $\mathbf{3 a}$ and $\mathbf{4 a}$ indicates that the sequence occurs without erosion of the enantioselectivity during the thioether reduction step. This method was then extended to the preparation of a series of cyclobutenes $\mathbf{4 b} \mathbf{b} \mathbf{h}$, showing the compatibility of the reduction with the presence of silyl ethers and chlorides. This two-steps strategy thus constitutes a reliable method for the enantioselective synthesis of cyclobutenes $\mathbf{4}$ and is amenable to large scale synthesis, as illustrated with the preparation of cyclobutenes $\mathbf{4 a}, \mathbf{4 d}$ and $\mathbf{4 e}$.

As mentioned above, cyclobutenes exhibit a limited reactivity toward radical species, despite their reported reaction with alkyl xanthates ${ }^{6,7 b}$ and our own experience with addition of $\mathrm{BrCCl}_{3}$ or bromomalonate (see $\mathrm{SI}$ ). Cyclobutene $4 \mathrm{a}$ was thus submitted to the photocatalyzed radical addition of $\mathrm{EtSO}_{2} \mathrm{CN}$, considering the high electrophilicity of sulfonyl radicals and their known efficient additions onto olefins, including cyclic ones. ${ }^{15}$ Application of our recently described eosin-mediated olefin sulfonyl-cyanation (Eosin-Y, $\mathrm{K}_{2} \mathrm{HPO}_{4}, \mathrm{DMF}$, green LEDs), ${ }^{16}$ effectively furnished the addition product 5 a as the major all-trans-isomer (dr>19:1:1) (Table 1, entry 1), whose structure was unambiguously assigned through $X$-ray diffraction studies (XRDS). This shows that the sulfonyl radical approaches anti relative to the oxazolidinone moiety, the cyanide group being then delivered anti relative to the bulky sulfonyl fragment. Although the stereoselectivity was high, yields were not satisfactory, particularly when scaling up was envisioned. For instance, $47 \%$ yield of 5 a was obtained when the reaction was performed on $24 \mathrm{mmol}$ scale. An alternative way to generate the electrophilic sulfonyl radical was thus looked for. Recent studies by Melchiorre et al. ${ }^{17}$ showed that photocatalysts having high triplet energy levels ${ }^{18}$ (around $70 \mathrm{kcal}^{\mathrm{mol}}{ }^{-1}$ ), such as 
p-anisaldehyde and benzophenone (BP), are able to sensitize alkyl halides and could be engaged in atom transfer radical additions (ATRA). It was anticipated that such catalysts might be able to activate sulfonyl cyanides in a similar way.

Using UV-A irradiation (325-400 nm) and $\mathrm{MeSO}_{2} \mathrm{CN}, p$-anisaldehyde or BP (Table 1, entries 3,5) effectively mediated the addition process leading to $\mathbf{5 b}$ in good yields, thus illustrating the first example of a triplet photosensitized olefin sulfonylcyanation. Reaction under UV-A in the absence of $p$-anisaldehyde also provided $\mathbf{5 b}$ albeit in much lower yield, as a result of direct absorption by substrate $\mathbf{4 a}$ at $325-400 \mathrm{~nm}(\mathrm{SI})$, (Table 1, entry 4). The critical role of $p$-anisaldehyde in this process is highlighted when using oct-1-ene, which does not absorb light in the 325-400 nm region. Sulfonyl-cyanation of oct-1-ene thus led to the desired product, with $>95 \%$ conversion ( $97 \%$ isolated yield after $24 \mathrm{~h}$ ), in the presence of $p$-anisaldehyde and only $25 \%$ in its absence after $20 \mathrm{~h}$ irradiation (see $\mathrm{SI}$ ). A similar trend was observed with $p$-TolSO $\mathrm{CN}_{2} \mathbf{5 c}$ being formed in only $7 \%$ in the absence of $p$-anisaldehyde (Table 1, entries 6-7). The reaction was also performed at $254 \mathrm{~nm}$, leading to complete consumption of $\mathbf{4 a}$ and the formation of a complex mixture in which $\mathbf{5 b}$ was absent, in contrast with literature reports $^{19}$ (Table 1, entries 8-9). Finally, several control experiments were performed (SI). For instance, in the absence of light, no trace of cyanosulfone $\mathbf{5 b}$ was observed. When the sulfonyl-cyanation of $\mathbf{4 a}$ was carried out using $\mathrm{MeSO}_{2} \mathrm{CN}$ and $p$ anisaldehyde (20 mol \%), but in the presence of a triplet quencher such as 2,5-dimethylhexa-2,4-diene (20 mol \%), 5b could not be detected after $20 \mathrm{~h}$ of irradiation (SI). A similar result was observed in the presence of pyridazine, which possesses a lower triplet-state energy than $p$-anisaldehyde.

The results above are consistent with a mechanism involving energy transfer from the excited triplet state of the sensitizer to the sulfonylcyanide. Alternative mechanisms involving photoinduced electron transfer from triplet $p$-anisaldehyde or BP to the sulfonylcyanide are calculated to be thermodynamically less favorable (see $\mathrm{SI}) .^{20}$ The efficiency of the photosensitizer can be assessed by comparing the photochemical quantum efficiency for the formation of $\mathbf{5 b}$ in the absence and presence of the sensitizer. The quantum yield for the formation of $\mathbf{5 b}$ from $\mathbf{4 a}$, in the absence of photosensitization, was determined to be 0.09 (determined at low conversion using $334 \mathrm{~nm}$ monochromatic irradiation, see SI). The same reaction conducted in the presence of $p$-anisaldehyde afforded a 1.8-fold increase in product yield. Because $4 a$ absorbs at the excitation wavelength, the observed yield must be corrected for the background reaction and internal filter effects, providing a value of 0.96 for the quantum yield of formation of $\mathbf{5 b}$ from excited $p$-anisaldehyde (see $\mathrm{SI}$ ). A value close to unity implies that the sequence of reactions leading to the formation of $\mathbf{5 b}$ is particularly efficient, or that it may involve a radical chain reaction with a turnover $>1$. Importantly, the transformation is intrinsically 10 -fold faster when sensitized vs direct irradiation. This, combined with a clean photochemical process, allows the reaction to be conducted on a multi-gram scale using small solvent volumes. Our results suggest that energy transfer from the triplet excited state anisaldehyde ${ }^{21}$ or $\mathrm{BP}^{22}$ to $\mathrm{RSO}_{2} \mathrm{CN}_{\text {al- }}$ lows the formation of the sulfonyl-cyanide excited triplet, which undergoes homolytic cleavage of the $\mathrm{O}_{2} \mathrm{~S}-\mathrm{CN}$ bond. The electrophilic sulfonyl radical thus formed would then add onto the less substituted end of the cyclobutene double bond, to generate a $\beta$-sulfonyl radical, finally trapped by $\mathrm{RSO}_{2} \mathrm{CN}$, leading to the product and the $\mathrm{RSO}_{2}$ radical, ready to sustain the radical chain reaction $(\mathrm{SI})$.

Table 1. Photosensitized sulfonyl-cyanation of cyclobutene 4 a.

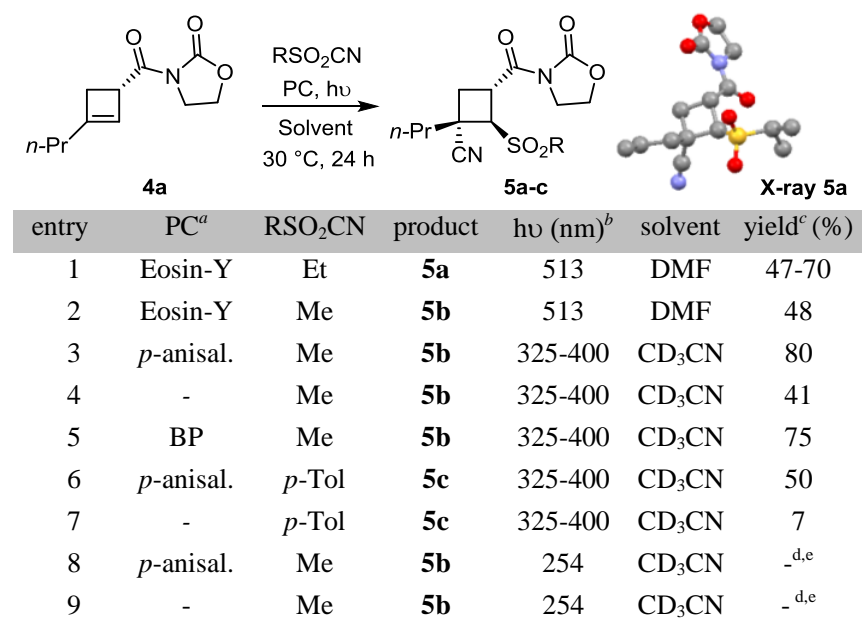

${ }^{a} \mathrm{RSO}_{2} \mathrm{CN}$ (2 equiv); Photocatalysts (PC): Eosin-Y ( $\left.2 \mathrm{~mol} \%\right) ; p$-anisal.: $p$-anisaldehyde ( $\left.20 \mathrm{~mol} \%\right) ; \mathrm{BP}$ : benzophenone (20 mol \%). ${ }^{b}$ Green LED (513 nm); UV-A (325-400 nm). ${ }^{c}$ NMR yield. ${ }^{d}$ complex mixture. ${ }^{e}$ Reaction performed in a quartz vessel. 
The scope of the sulfonyl-cyanation was then established using Eosin-Y (Method A) or $p$-anisaldehyde (Method B) as photosensitizers for comparison purposes. Overall, reactions were cleaner with method B, easier to carry out and leading to higher yields and more straightforward purifications on larger scale (Scheme 3). Better yields were also observed using less hindered $\mathrm{MeSO}_{2} \mathrm{CN}$. The diastereoselectivity of the sulfonyl-cyanation reaction was in all cases high (dr>19:1:1) in favor of the all-trans-product. The stereochemistry of $\mathbf{5 b}, \mathbf{5 d} \mathbf{d}-\mathbf{q}$ was assigned based on the configuration of $\mathbf{5 a}$ and $\mathbf{5 c}$, obtained through XRDS (vide supra). The yield decreased significantly for hindered cyclobutenes (e.g. $\mathbf{5 m}$ - $\mathrm{n}$ bearing a bulky TBDMS substituent). The process is compatible with chains bearing a chlorine atom (5i-j) and with silyl ethers $(\mathbf{5} \mathbf{d}-\mathbf{g})$. The reaction is not restricted to methyl, ethyl or arylsulfones but may be extended to functionalized sulfonyl cyanides (e.g. 5o-q), albeit with lower efficiency. Interestingly, these mild conditions also prevent desulfonylation of the alkanesulfonyl radical and formation of the corresponding alkyl radical.

Scheme 3. Eosin-Y or p-anisaldehyde-mediated sulfonyl-cyanation of cyclobutenes $\mathbf{4 a - h}$.

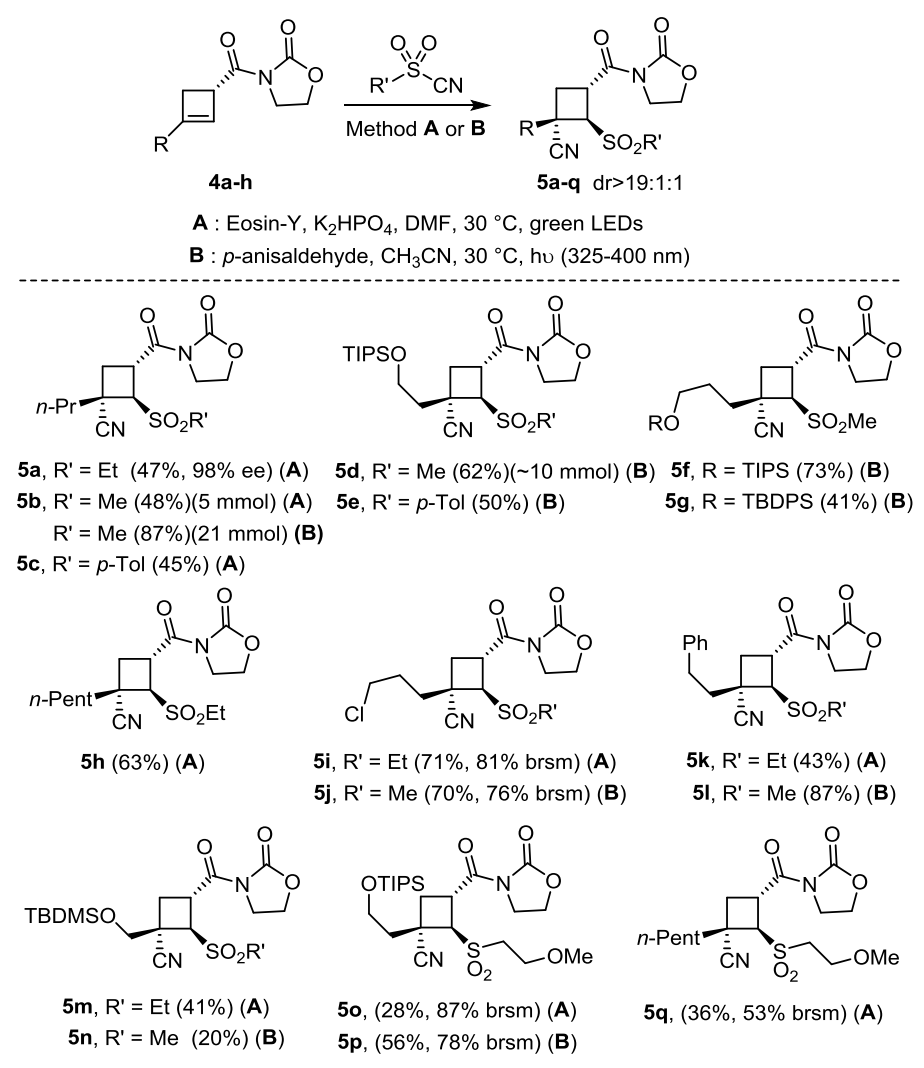

Our efforts were then directed toward the functionalization of these highly substituted cyclobutanes, first focusing on the opening of the 4-membered ring. ${ }^{23}$ This strategy would open an access to enantiopure nitriles $\gamma$ to a carbonyl group, and bearing an all-carbon quaternary stereocenter (III, Scheme 1), through an indirect cyanation approach, which complements the usual cyanations in $\alpha$ and $\beta$ positions. The regioselective ring-opening was performed through a ketyl radical, generated from $\mathrm{N}$-acyloxazolidinones 5 using $\mathrm{Sml}_{2}$, the ensuing fast cyclobutyl radical-anion ring opening $\left(\mathrm{k}^{\sim} 3 \times 10^{4} \mathrm{~s}^{-1}\right),{ }^{24}$ leading to a stabilized radical $\alpha$ - to the sulfone. Although the generation of a ketyl radical from amides or $N$-acyloxazolidinones remains challenging and less documented than for ketones, ${ }^{25}$ reduction and fragmentation was found to proceed in less than $1 \mathrm{~h}$ at $78{ }^{\circ} \mathrm{C}$ using a $1: 3 \mathrm{Sml}_{2}-\mathrm{H}_{2} \mathrm{O}^{26}$ mixture and 4 equiv of $\mathrm{Sml}_{2}$ (For optimization, see Tables $\mathrm{S} 3$ and S4). Reaction conditions were shown to tolerate functionalized alkyl groups such as aryl, chloride, protected alcohols and ethers and led generally to better yields with methylsulfones (e.g. $\mathbf{n}$ vs 60 ) (Scheme 4). Finally, large scale synthesis is allowed, as exemplified by the preparation of nitrile $6 \mathrm{e}$ in excellent yield on $5 \mathrm{mmol}$ scale. 
Scheme 4. $\mathrm{Sml}_{2}$-mediated cyclobutane-ring opening of cyclobutanes $\mathbf{5 a - q}$.

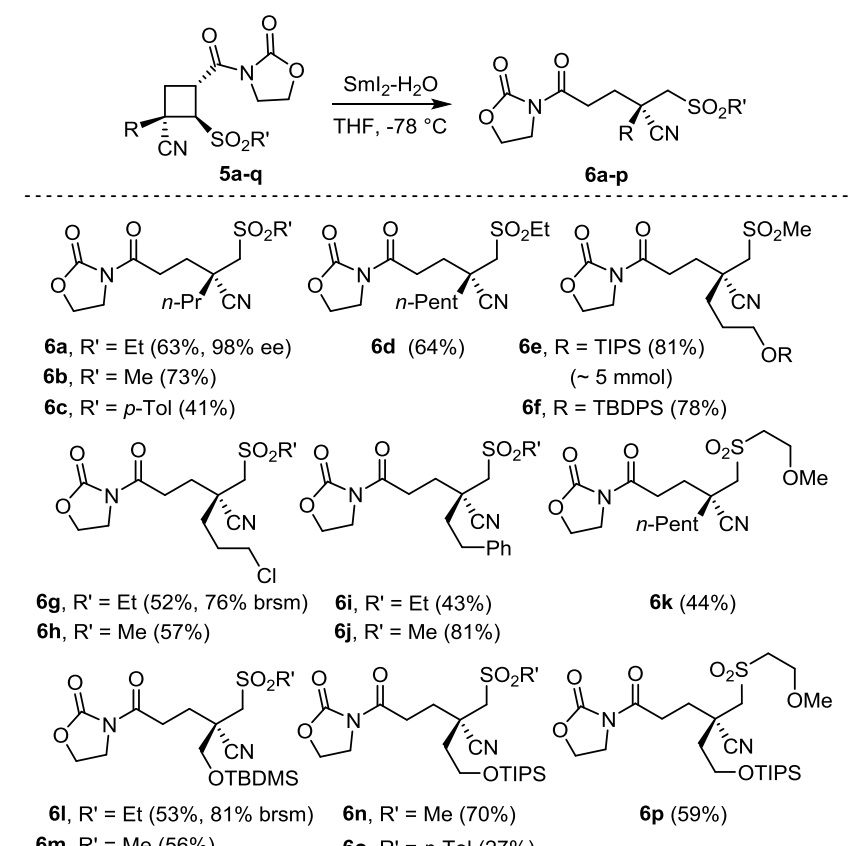

Cyclobutanes such as $\mathbf{5} \mathbf{d}$ and $\mathbf{5} \mathbf{f}$ were also functionalized further, relying on the easy removal of the alkanesulfonyl group (Scheme 5). One-pot elimination of the oxazolidinone and sulfonyl groups in $\mathbf{5 d}$ and $\mathbf{5} \mathbf{f}$ under mild basic conditions, ${ }^{27}$ thus provided an access to homochiral cyclobutenes $\mathbf{7 a - b}$, ready for further manipulations. For instance, conjugate addition of pyrrolidine to $\mathbf{7 b}$ furnished the tetra-substituted cyclobutane 9 in high yield and excellent diastereocontrol. ${ }^{28}$ Nitromethane under basic conditions was also shown to add readily to 7a, providing 8 in $69 \%$ yield. In both cases, the nucleophilic fragment approached anti relative to the bulkier alkyl chain. Steric differentiation between the linear $\mathrm{CN}$ group and any other substituent on the quaternary stereocenter is noteworthy as it allows a high level of stereocontrol during the conjugate addition. Finally, ozonolysis of 7 a led to the sensitive tricarbonylated compound $10{ }^{29}$ further highlighting the synthetic potential of these polyfunctionalized cyclobutenes.

Scheme $\mathbf{5}$. Further functionalization of cyclobutanes $\mathbf{5 d}$ and $\mathbf{5 f}$.

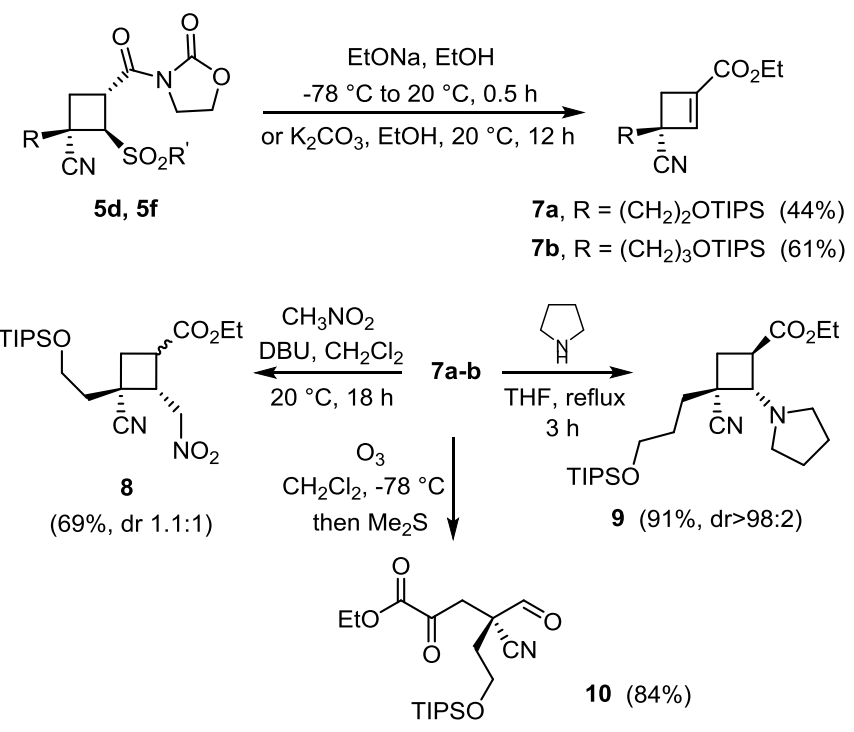




\section{Conclusions}

In summary, we report in this article an unprecedented $p$-anisaldehyde-photosensitized sulfonyl-cyanation of cyclobutenes, affording the corresponding cyanosulfones in high yields and diastereocontrol. An efficient synthesis of enantiopure cyclobutenes was also disclosed. This study demonstrates that highly electrophilic sulfonyl radicals can add efficiently to poorly reactive cyclobutenes. The sequence can be carried out on multi-gram scale with excellent reproducibility, affording enantiopure cyclobutanes which can then be elaborated further through ring-opening or sulfonyl group elimination. Studies are now ongoing to exploit further the radical chemistry of these cyclobutenes for applications in total synthesis of natural products.

\section{Author Contributions}

The manuscript was written through contributions of all authors. / All authors have given approval to the final version of the manuscript. $\$$ These authors contributed equally.

\section{REFERENCES}

(1) (a) Chen, D. Y.-K.; Pouwer, R. H.; Richard, J.-A. Chem. Soc. Rev. 2012, 41, 4631; (b) Wessjohann, L. A.; Brandt, W.; Thiemann, T. Chem. Rev. 2003, 103, 1625; (c) Namyslo, J. C.; Kaufmann, D. E. Chem. Rev. 2003, 103, 1485; (d) Lee-Ruff, E.; Mladenova, G. Chem. Rev. 2003, 103, 1449; (e) Seiser, T.; Saget, T.; Tran, D. N.; Cramer, N. Angew. Chem., Int. Ed. 2011, 50, 7740; (f) Hansen, T. V.; Stenstrøm, Y. Naturally occurring cyclobutanes. In Organic Synthesis: Theory and Applications, Hudlicky, T. Ed.; Elsevier: Oxford, UK, 2001; Vol. 5, p. 1; (g) Nakamura, M.; Chi, Y.-M.; Yan, W.-M.; Yonezawa, A.; Nakasugi, Y.; Yoshizawa, T.; Hashimoto, F.; Kinjo, J.; Nohara, T.; Sakurada, S. Planta Med. 2001, 67, 114; (h) Lee, F.-P.; Chen, Y.-C.; Chen, J.-J.; Tsai, I.-L.; Chen, I.-S. Helv. Chim. Acta 2004, 87, 463; (i) Liu, R.; Zhang, M.; Wyche, T. P.; Winston-McPherson, G. N.; Bugni, T. S.; Tang, W. Angew. Chem. Int. Ed. 2012, 51, 7503.

(2) (a) Cavitt, M. A.; Phun, L. H.; France, S. Chem. Soc. Rev. 2014, 43, 804; (b) Schneider, T. F.; Werz, D. B. Org. Lett. 2011, 13, 1848; (c) Schneider, T. F.; Kaschel, J.; Werz, D. B. Angew. Chem. Int. Ed. 2014, 53, 5404.

(3) For selected reports on the synthesis of cyclopropanes, see: (a) Lebel, H.; Marcoux, J.-F.; Molinaro, C.; Charette, A. B. Chem. Rev. 2003, 103, 977; (b) Ebner, C.; Carreira, E. M. Chem. Rev. 2017, 117, 11651; For selected reports on the synthesis of cyclobutanes, see: (c) Poplata, S.; Tröster, A.; Zou, Y.-Q.; Bach, T. Chem. Rev. 2016, 116, 9748; (d) Misale, A.; Niyomchon, S.; Maulide, N. Acc. Chem. Res. 2016, 49, 2444; (e) Xu, Y.; Conner Michael, L.; Brown, M. K. Angew. Chem. Int. Ed. 2015, 54, 11918; (f) Luparia, M.; Oliveira, M. T.; Audisio, D.; Frebault, F.; Goddard, R.; Maulide, N. Angew. Chem. Int. Ed. 2011, 50, 12631; (g) Fawcett, A.; Bilberger, T.; Aggarwal, V. K. Nat. Chem. 2019, 11, 117; (h) Andersen, C.; Ferey, V.; Daumas, M.; Bernardelli, P.; Guérinot, A.; Cossy, J. Org. Lett. 2019, 21, 2285.

(4) (a) Rubin, M.; Rubina, M.; Gevorgyan, V. Chem. Rev. 2007, 107, 3117; (b) Zhu, Z.-B.; Wei, Y.; Shi, M. Chem. Soc. Rev. 2011, 40, 5534; (c) Vincente, R. Synthesis 2016, 48, 2343; (d) Dian, L.; Marek, I. Angew. Chem. Int. Ed. 2018, 57, 3682; (e) Didier, D.; Delaye, P.-O.; Simaan, M.; Island, B.; Eppe, G.; Eijsberg, H.; Kleiner, A.; Knochel, P.; Marek, I. Chem. Eur. J. 2014, 20, 1038; (f) Zhang, F.-G.; Eppe, G.; Marek, I. Angew. Chem., Int. Ed. 2016, 55, 714; (g) Roy, S. R.; Didier, D.; Kleiner, A.; Marek, I. Chem. Sci. 2016, 7, 5989; (h) Müller, D. S.; Marek, I. Chem. Soc. Rev. $2016,45,4552$.

(5) Roy, S. R.; Eijsberg, H.; Bruffaerts, J.; Marek, I. Chem. Sci. 2017, 8, 334.

(6) Ferjančić, Z.; Čeković, Ž.; Saičić, R. N. Tetrahedron Lett. 2000, 41, 2979.

(7) (a) Yamago, S.; Ejiri, S.; Nakamura, E. Chem. Lett. 1994, 23, 1889; (b) Legrand, N.; Quiclet-Sire, B.; Zard, S. Z. Tetrahedron Lett. 2000, 41, 9815; (c) Ueda, M.; Doi, N.; Miyagawa, H.; Sugita, S.; Takeda, N.; Shinada, T.; Miyata, O. Chem. Commun. 2015, 51, 4204; (d) Doi, N.; Takeda, N.; Miyata, O.; Ueda, M. J. Org. Chem. 2016, 81, 7855.

(8) (a) Kimoto, H.; Muramatsu, H.; Inukai, K. Bull. Chem. Soc. Jpn. 1977, 50, 2815; (b) Kinney, W. A. Tetrahedron Lett. 1993, 34, 2715; (c) Leigh, W. J.; Zheng, K.; Nguyen, N.; Werstiuk, N. H.; Ma, J. J. Am. Chem. Soc. 1991, 113, 4993.

(9) Dange, N. S.; Robert, F.; Landais, Y. Org. Lett. 2016, 18, 6156.

(10) (a) Narasaka, K.; Hayashi, Y.; Shimadzu, H.; Niihata, S. J. Am. Chem. Soc. 1992, 114, 8869; (b) Schotes, C.; Mezzetti, A. Angew. Chem., Int. Ed. 2011, 50, 3072; (c) Kang, T.; Ge, S.; Lin, L.; Lu, Y.; Liu, X.; Feng, X. Angew. Chem., Int. Ed. 2016, 55, 5541; (d) Kumar, R.; Tamai, E.; Ohnishi, A.; Nishimura, A.; Hoshimoto, Y.; Ohashi, M.; Ogoshi, S. Synthesis 2016, 48, 2789; (e) Garcia-Morales, C.; Ranieri, B.; Escofet, I.; Lopez-Suarez, L.; Obradors, C.; Konovalov, A. I.; Echavarren, A. M. J. Am. Chem. Soc. 2017, 139, 13628.

(11) (a) Protopopova, M. N.; Doyle, M. P.; Müller P.; Ene, D. G. J. Am. Chem. Soc. 1992, 114, 2755; (b) Lou, Y.; Horikawa, M.; Kloster, R. A.; Hawryluk N. A.; Corey, E. J. J. Am. Chem. Soc. 2004, 126, 8916; (c) Goto, T.; Takeda, K.; Shimada, N.; Nambu, H.; Anada, M.; Shiro, M.; Ando, K.; Hashimoto, S.-I. Angew. Chem., Int. Ed. 2011, 50, 6803; (d) Boruta, D. T.; Dmitrenko, O.; Yap, G. P. A.; Fox, J. M. Chem. Sci. 2012, 3, 1589; (e) Cui, X.; Xu, X.; Lu, H.; Zhu, S.; Wojtas, L.; Zhang, X. P. J. Am. Chem. Soc. 2011, 133, 3304.

(12) Zhang, F.-G.; Marek, I. J. Am. Chem. Soc. 2017, 139, 8364.

(13) Sakai, K.; Kochi, T.; Kakiuchi, F. Org. Lett. 2013, 15, 1024.

(14) (a) Evans, D. A.; Black, W. C. J. Am. Chem. Soc. 1993, 115, 4497; (b) Evans, D. A.; Trotter, B. W.; Cote, B.; Coleman, P. J. Angew. Chem. Int. Ed. 1998, 36, 2741. 
(15) Chatgilialoglu, C.; Mozziconacci, O.; Tamba, M.; Bobrowski, K.; Kciuk, G.; Bertrand, M. P.; Gastaldi, S.; Timokhin, V. I. J. Phys. Chem. A 2012, 116, 7623.

(16) (a) Pirenne, V.; Kurtay, G.; Voci, S.; Bouffier, L.; Sojic, N.; Robert, F.; Bassani, D. M.; Landais, Y. Org. Lett. 2018, 20, 4521. (b) Sun, J.; Li, P.; Guo, L.; Yu, F.; He, Y.-P.; Chu, L. Chem. Commun. 2018, 54, 3162.

(17) Arceo, E.; Montroni, E.; Melchiorre, P. Angew. Chem. Int. Ed. 2014, 53, 12064.

(18) (a) Albini, A. Synthesis 1981, 249; (b) Lu, Z.; Yoon, T. P. Angew. Chem. Int. Ed. 2012, 51, 10329; (c) Farney, E. P.; Yoon, T. P. Angew. Chem. Int. Ed. 2014, 53, 793; (d) Alonso, R.; Bach, T. Angew. Chem. Int. Ed. 2014, 53, 4368.

(19) UV-mediated sulfonyl-cyanation of olefins was reported earlier, but the olefin was used as a co-solvent, see: Pews, R. G.; Evans, T. E. J. Chem. Soc., Chem. Commun. 1971, 1397.

(20) Sulfonyl-cyanation of $n$-octene using 9,10-dimethylanthracene, a strong electron-donor, but with a low triplet energy, led to the formation of the desired nitrile with $0=0.13($ (?ex $=365 \mathrm{~nm})(\mathrm{SI})$.

(21) Görner, H.; Kuhn, H. J. J. Phys. Chem. 1986, 90, 5946.

(22) (a) Yang, N. C.; Kimura M.; Eisenhardt, W. J. Am. Chem. Soc. 1973, 95, 5058; (b) Koyanagi M.; Goodman, L. J. Phys. Chem. 1971, 55, 2959.

(23) Kakiuchi, K.; Minato, K.; Tsutsumi, K.; Morimoto, T.; Kurosawa, H. Tetrahedron Lett. 2003, 44, 1963.

(24) Tanko, J. M.; Paige Phillips, J. J. Am. Chem. Soc. 1999, 121, 6078.

(25) (a) Kagan, H. B.; Namy, J. L. in Topics in Organometallic Chemistry, Lanthanides: Chemistry and Use in Organic Synthesis, Ed. S. Kobayashi, Springer, Berlin, 1999, p. 155; (b) Procter, D. J.; Flowers II, R. A.; Skrydstrup, T. Organic Synthesis Using Samarium Diiodide: A Practical Guide. RSC Publishing, 2010.

(26) (a) Szostak, M.; Spain, M.; Eberhart, A. J.; Procter, D. J. J. Am. Chem. Soc. 2014, 136, 2268; (b) Hansen, A. M.; Lindsay, K. B.; Antharjanam, P. K. S.; Karaffa, J.; Daasbjerg, K.; Flowers II, R. A.; Skrydstrup, T. J. Am. Chem. Soc. 2006, 128, 9616.

(27) Simpkins, N. S. Sulphones in Organic Synthesis, Tetrahedron Organic Chemistry Series, Eds. Baldwin, J. E., Magnus, P. D., Pergamon Press, Oxford, 1993, Vol. 10, p. 262.

(28) (a) Johnson, C. R.; De Jong, R. L. J. Org. Chem. 1992, 57, 594; (b) Dowling, M. S.; Vanderwal, C. D. J. Org. Chem. 2010, 75, 6908.

(29) Jung, M. E.; Deng, G. J. Org. Chem. 2012, 77, 11002. 